\title{
Evaluating the Iran Mobile Communication Operators by Analytical Network Process (ANP)
}

Hemmati S, Shapouri F and Keramati $A^{*}$

Industrial Engineering Department, Faculty of Engineering, University of Tehran, Iran

\begin{abstract}
The arrival of the mobile telecommunications service industry and its rapid and widespread growth is the most significant developments in the fields of communication. The aim of this study is to propose a decision-making structure to determine the appropriate Global System for Mobile Communications (GSM) operator. There are varieties of driving factors involved in choosing the most suitable GSM's operator, and all these factors have positive and negative interactions with each other; in this regard, we apply an appropriate multi-criteria decision- making method. Due to the interdependency between these criteria, we use Analytic Network Process (ANP) that generalizes Analytic Hierarchical Process (AHP) by considering the interdependencies among factors. The results of this method illustrate that customer satisfaction and word of Mouth are the most important factors in selecting GSM's operators in Iran. The proposed structure provides valuable insight into the process of GSM's operator selection for GSM managers and practitioners. It can be applied as a practical assessment tool providing an evaluation of GSM operator's market share and identifies areas of weakness that negatively affect success in market share.
\end{abstract}

Keywords: Analytical Network Process; Mobile Communication Operator; Customer; Multi Criteria Decision Making; Iran

\section{Introduction}

In recent years, communication has been growing rapidly in Iran as all over the world. People around the today's global world have the common need to communicate with friends, family, and colleagues wherever they are. Within this common need, people have different communication requirements. Some may need constant and real time access to their email; others may want to download music and games; others just want to talk. However, all of them desire simplicity and transparency. This situation increases the usage of mobile telecommunications service among people and makes them require mobile communication operators. An increasing demand in the mobile phone sector brings the rise in the mobile communication operators.

Actually, the studies made on the growth of the mobile communication have confirmed that there are now more mobile phone subscribers than fixed line subscribers. In Iran, a mobile telephony service was launched by the government-owned Iran Mobile Telecom "MCI" in 1992. After 12 years, the entrance of new private operators "Taliya" in 2004 ended a longstanding monopolistic market structure. In September 2005 "Irancell" in a partnership with MTN, the largest mobile telephony operator currently in the Middle East and Africa, started its own mobile telephony service as a second operator [1]. Eighteenth years after the introduction of mobile telephony into Iran, the mobile communications development index has a penetration rate of approximately $91 \%$ that show a good growth in recent years (Figure $1)$.

Since the mobile communications have evolved from an isolated luxury of the rich to the new necessity of the masses, the operators had started to develop their sale and service strategies based on customers preferences over time [2]. The large scale of the products and services on the market reflects the social and financial status of users, moreover their preferences and their attitudes towards usage of them. In such a market environment, choosing a mobile operator becomes an important problem to a costumer who has to select the most appropriate communication operators. So, the mobile operator selection can be considered as a complex multi-criteria decision problem since the people expectations differ from different functional areas within a society. Hence, the main objective of this paper is to propose a structure to decide on the most appropriate mobile communication operators in the marketplace.

Decision-Making problem is the process of defining the decision goals, gathering relevant information, and selecting the optimal alternative [3]. There are many MCDM methods have been developed such as the Elimination and Choice Translating Reality (ELECTRE), the Technique for Order Preference by Similarity to Ideal Solution (TOPSIS), The Analytic Hierarchy Process (AHP), but these methods do not deal with the interdependence among elements. Analytic Network Process (ANP) is a relative new MCDM method recently introduced by [4] which can deal with all kinds of dependences systematically. It can be used as an analysis tool in those problems where there are interactions and dependencies among the elements of a system [5].

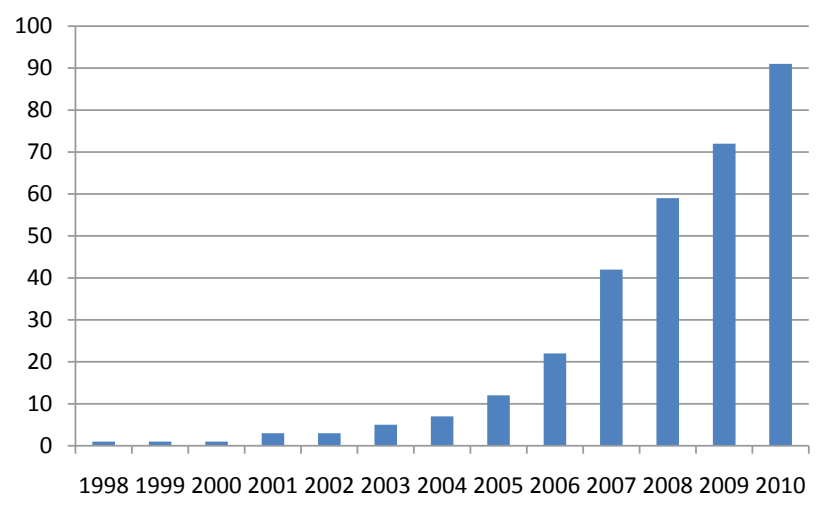

Figure 1: Mobile communications development (www.worldbank.org).

*Corresponding author: Keramati A, Industrial Engineering Department, Faculty of Engineering, University of Tehran, Iran. Tel. + 982188021067 ; Fax: + 9821 82084194; E-mail: keramati@ut.ac.ir

Received July 05 2013; Accepted August 22, 2013; Published August 26, 2013

Citation: Hemmati S, Shapouri F, Keramati A (2013) Evaluating the Iran Mobile Communication Operators by Analytical Network Process (ANP). J Telecommun Syst Manage 2: 109. doi:10.4172/2167-0919.1000109

Copyright: ( 2013 Hemmati S, et al. This is an open-access article distributed under the terms of the Creative Commons Attribution License, which permits unrestricted use, distribution, and reproduction in any medium, provided the original author and source are credited. 
In this paper we identified factors that influence on the preference for a specific mobile communication operator in Iran .This is realized through a survey conducted among the target group, the experiences of the telecommunication sector experts and the studies in the literature. Then we define the effects of these factors on each other and construct the network model. Finally, by applying the proposed ANP structure (Table 4), we determine the most appropriate mobile communication operators in the market place and the most important factors that effect on choosing mobile communication operator. Therefore, mobile communication operators can take this information into the consideration for exploring the factors affecting market share and deciding for the actions to increase their company's market share.

The rest of the paper is organized as follows: in the next section, the previous research in the field is presented. In Section 3, the research methodology for selecting the mobile communication operators is illustrated. This section consists of illustration of different phases of the proposed ANP structure. In Section 4, the results of the utilized method are presented. The next two sections provide discussion on the obtained results and highlight some managerial implications of the study, respectively. Finally, the concluding remarks and future research directions are provided in Section 7.

\section{Literature Review}

Telecommunications has entered a new age of development with advanced technology and increased competition with established players. The technological advances in the telecommunication sector are associated with an uninterrupted growth of the mobile sector. The prime focus of the service providers is to create a loyal customer [6]. Progress in information technologies and telecommunications over the last two decades has created a knowledge society. Effective customer management is becoming increasingly important. Understanding and analyzing customer preference in a scientific way will be a potential competitive advantage for the existing operators as well as new-comers [7].

There are several studies which concern with evaluating telecommunication and using Multi Criteria Decision Making (MCDM) techniques. Tosun et al. [7] presented a decision model, based on ANP, in order to evaluate and rank the GSM market in Turkey. A quantitative analysis was conducted with the customers in order to assess the importance of the related factors and forecast the market shares of the Turkish mobile communication operators. Erginel and Şenturk [8] presented the ranking of the GSM in turkey with identifying many criteria and sub-criteria with using Fuzzy Analytic Network Process (FANP). GülfemIșıklar et al. [9] proposed a MCDM approach to evaluate the mobile phone options in respect to the users' preferences order. Firstly, the most desirable features influencing the choice of a mobile phone are identified. Two MCDM methods (AHP and TOPSIS) are used in the evaluation procedure. Giokas and Pentzaropoulos [10] used two quantitative instruments: AHP and DEA in order to compare and then rank all (30) OECD member states as regards efficiency in telecommunications. Debnath and Shankar [6] employed DEA to compare the relative efficiency of mobile service providers in India. The summary of related studies is depicted in Table 1.

Apart from the telecommunication related subjects, there are several studies which concern with other field such us information technology, risk assessment, supply chain and etc. which are using MCDM approaches. Keramati and Salehi [11] investigated relative importance of website success factors in selecting the most preferred website through applying an ANP approach and Updated Delone and McLean information system success model. Ergu et al. [12] proposed a maximum eigenvalue threshold as the consistency index for the ANP in risk assessment and decision analysis. The proposed threshold is mathematically equivalent to the consistency ratio (CR). Keramati and Sangari [13] suggested novel success framework for Customer Relationship Management (CRM) based on a conceptual implementation model to identify associated critical factors and their contribution to overall success/failure. FANP is applied to identify the relative importance of each factor in successful implementation of CRM. Vinodh et al. [14] used FANP approach for the supplier selection process. Based on supplier selection weighted index, the best supplier has been determined. Salehi et al. [15] proposed a framework to investigate the factors of mobile web success in the context of e-commerce. They chose Updated Delone and Mclean IS success model to extract significant mobile web success factors and then the ANP approach is applied for investigating the relative importance of each factor and ranking alternative mobile webs. Chen and Zheng [16] suggested that five main elements can help to select the best MC product project for the MC provider and used Fuzzy Analytical Hierarchy Process (FAHP) for the specific new product projects selection process. Desheng $\mathrm{Wu}$ [17] proposed an integrated multi-objective decision-making process by using ANP and mixed integer programming to optimize supplier selection process. Maggie et al. [18] presented an AHP-based model and applied it to a real case study to examine its feasibility in selecting a vendor for a telecommunications system. They indicated that the use of the proposed model can be improving the group decision making in selecting a vendor that satisfies customer specifications.

\section{Research Methodology}

In this section, the method of data gathering and analysis employed for evaluating the mobile communication operators will be discussed.

\section{Data gathering}

In order to elicit required data and assess information on preferences of the respondents when selecting a mobile communication operator, a questionnaire has been designed. This questionnaire contained 226 questions including a series of pair wise comparisons. These pair wise comparisons are based on Saaty's nine point scale Table 3 and represent

\begin{tabular}{|c|c|c|}
\hline References & Research Objective & Techniques \\
\hline Tosun et al & Evaluate the GSM market in Turkey & ANP \\
\hline Erginel et al & Rank the GSM in Turkey & FANP \\
\hline Gülfemlşıklar et al & Evaluate the mobile phone options & AHP \&TOPSIS \\
\hline $\begin{array}{l}\text { Giokas and } \\
\text { Pentzaropoulos }\end{array}$ & $\begin{array}{c}\text { Compare and rank all OECD member } \\
\text { states as regards efficiency in } \\
\text { telecommunications }\end{array}$ & DEA \& AHP \\
\hline $\begin{array}{l}\text { Debnathand } \\
\text { Shankar }\end{array}$ & $\begin{array}{c}\text { Compare the relative efficiency of mobile } \\
\text { service providers in India }\end{array}$ & DEA \\
\hline Keramati et al & $\begin{array}{l}\text { Suggest a framework for CRM to identify } \\
\text { associated critical factors and their } \\
\text { contribution to overall success/failure }\end{array}$ & FANP \\
\hline Salehi et al & $\begin{array}{l}\text { Proposes a framework to investigate } \\
\text { the factors of mobile web success in the } \\
\text { context of e-commerce }\end{array}$ & ANP \\
\hline Chen et al & $\begin{array}{l}\text { select the best MC product project for the } \\
\text { MC provider }\end{array}$ & FAHP \\
\hline Maggie et al & $\begin{array}{c}\text { vendor selection of a telecommunications } \\
\text { system }\end{array}$ & $\mathrm{AHP}$ \\
\hline DajiErgu et al & Risk assessment and decision analysis. & ANP \\
\hline D.Wu & Optimize supplier selection process & $\begin{array}{l}\text { ANP and } \\
\text { mixed integer } \\
\text { programming }\end{array}$ \\
\hline Vinodh et al & Supplier selection & FANP \\
\hline
\end{tabular}


how many times one criteria is more important than another criteria (both in the same cluster) with respect to an element in other cluster which have interaction with it. The respondents, who are using mobile communication in daily life, were about 125 people in the age groups $12+$ years. 56 percent of them were male and 44 percent were female that were divided in three age groups. The first age group includes people between 12 to 25 years who studying in high school and also under graduate and graduate students in universities and forms 34 percent of respondents. The second age group is between 25 to 40 years including graduate and post graduate students in universities, university and government staff and householders and forms 40 percent of respondents. Finally, the third age group includes university and government staff, householders and retired people over 40 years and forms 40 percent of respondents. This information is summarized in Table 2 .

\section{Modeling the problem with ANP}

ANP is a methodology recently introduced by Saaty which generalizes a widely used multi-criteria decision making tool, the AHP, by replacing hierarchies with networks [19] (Figure 2). It is a practical and useful technique for ranking and selection of a number of externally determined alternatives in those problems where there are interactions and dependencies among the elements of a system. It is noteworthy to mention that decisions obtained from a network can be significantly different from those obtained from a more complex hierarchy [20]. Also, the ANP can change qualitative judgments into quantitative values; so, it can be applied in decision areas that both qualitative and quantitative criteria exist.

In general, there are two different kinds of ANP: a model which based on feedback and the series system model. The series model is a linear top to bottom structure. In the feedback-based model, the components of system link together to form a network structure [4]. The control criteria for ANP analysis, provides overriding criteria for comparing each type of interaction that is intended by the network representation. There are two types of control criteria [21]. A control criterion may be directly connected to the structure as the goal of a hierarchy if the structure is in fact a hierarchy. Otherwise a control criterion does not connect directly to the structure but induces comparisons in a network. The literature review on mobile communication systems reveals that there is only a handful of research regarding selection of mobile communication operator. Also, we have not encountered a research on the selection of mobile communication operator in Iran. Therefore, we propose a formal MCDM based approach to address this decision. The evaluation procedure of this paper consists of five main steps as summarized in Figure 3 and the detailed descriptions of each step are elaborated as follows:

\begin{tabular}{|c|c|c|}
\hline Age Group & Percentage & Number \\
\hline F1:12-25 & $34.40 \%$ & 43 \\
\hline F2:25-40 & $40.80 \%$ & 51 \\
\hline F3:40+ & $24.80 \%$ & 31 \\
\hline
\end{tabular}

Table 2: The respondents.

\begin{tabular}{|c|c|}
\hline Intensity of importance & Definition \\
\hline 1 & Equal \\
\hline 3 & Moderately more Important \\
\hline 5 & Strongly more Important \\
\hline 7 & Very Strongly more Important \\
\hline 9 & Extremely more Important \\
\hline $2,4,6,8$ & Intermediate values of Importance \\
\hline
\end{tabular}

Table 3: The numerical rating assosiated with pairwise comparisons [19].

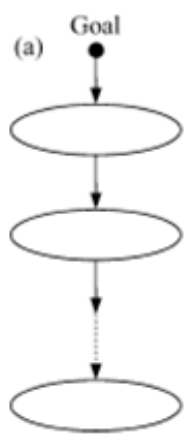

(b)

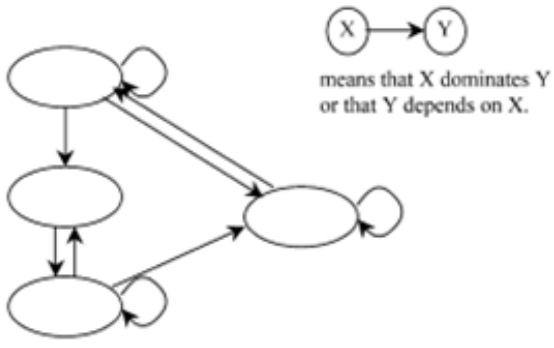

Figure 2: (a) AHP Model Structure, (b) ANP Model Structure.

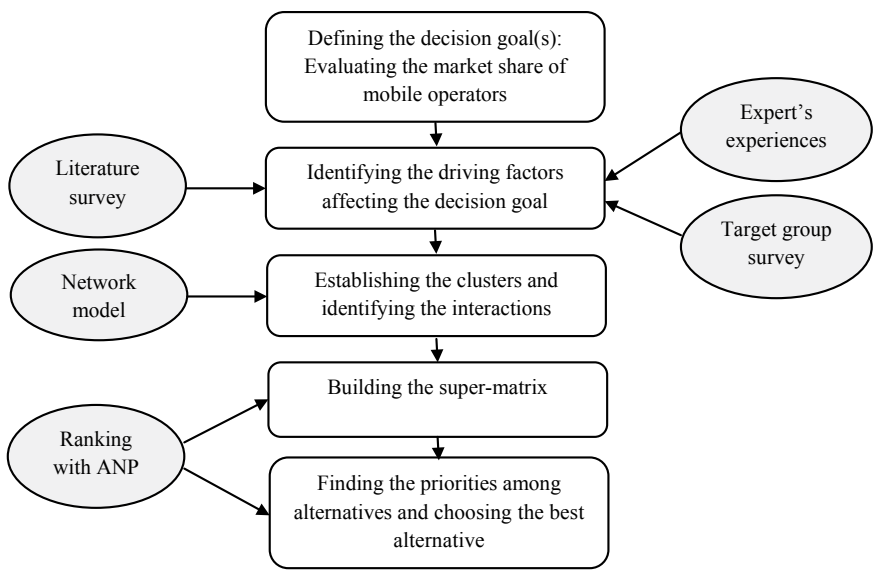

Figure 3: The proposed ANP procedure.

\begin{tabular}{|c|c|}
\hline A-Tariff & D-Extra features \\
\hline A1- SIM card price & D1- Operator's Brand or Reputation \\
\hline A2- Calling costs & D2- Environmental Responsibility \\
\hline A3- Other costs & D3- Base Stations' Placement \\
\hline A4- message cost & D4- Sponsorship \\
\hline C-After sales services & B-Services \\
\hline C1- Customer Satisfactions & B1- Coverage Area \\
\hline C2- Reliability & B2- Official Website \\
\hline C3- Extra services & B3- Sales and service center \\
\hline E-Advertisement & F-Customer segment \\
\hline E1-media & F1- 12-25 \\
\hline E2- Internet & F2- 23-40 \\
\hline E3- Word of Mouth & \multicolumn{2}{|c}{ F3- 40+ } \\
\hline E4- Print Media & G-Alternatives \\
\hline & G1- MCl \\
\hline \multicolumn{2}{|c|}{ G2- Iran cell } \\
\hline \multicolumn{3}{|c|}{ G3- Taliya } \\
\hline
\end{tabular}

Table 4: List of clusters and criteria used by the proposed ANP model.

Analyzing the problem and determining the goals: Decisionmaking is the process of defining the decision goals, gathering relevant information, and or prioritizing the existing alternative [21]. Hence, the first phase is to define the decision goals, which is selecting the desirable mobile communications operator in Iran.

Identifying the driving factors: In order to take proper decision and choose the desirable mobile operators, the most important features and 
characteristics of mobile operators, services and customers influencing the decision should be explored. These characteristics form the most reasonable criteria list that influences the problem. In this regards, the detailed examination of mobile operator's websites was done to drive the characteristics of them. And to drive the characteristics of services and customers a survey conducted among the target group and the experiences of the telecommunication sector experts have been combined. In addition, literature review was conducted and similar studies were examined in depth.

All these criteria suggest the most reasonable criteria list to be useful in the choice of mobile communication operators.

Establishing the clusters and identifying the relationships: We have classified the determined factors into six categories as the ANP's clusters: "Tariff", "Services", "After sales services", "Extra features", "Customer segments" and "Advertisement". Each cluster consists of several criteria which are familiar in specific aspect. These clusters and their factors are summarized in Table 5 with a specific code letter. By establishing the clusters of ANP model and identifying their inner, outer interactions, the network structure can be identified. This network spreads out in all directions and involves cycles between clusters and loops within the same cluster [19]. Arrows of the network denote interactions between clusters known as outer dependency. The directions of the arrows represent dependence, whereas loops signify inner dependency of the criteria in a cluster. The clusters and the inner, outer interactions between them are depicted in Figure 4. We utilize the "Super Decision 1.6" software to construct this network model.

Building the super-matrix: In this step super-matrix is made according to the network built in pervious step. Super-matrix is a partitioned matrix, where each sub-matrix is composed of a set of relationships between two clusters. If there is no linkage between clusters, then the relevant sub-matrix would be zero. However, if there is some relationship, then the entry would be non-zero. Also, an inner dependence would exist if there is a linkage within the criteria of a cluster [21]. Figure 5 show a super-matrix.

In the above super-matrix, $W_{i j}$ denotes the sub-matrixes which mean that cluster $i$ influences the cluster $i$. Each column of $W_{i j}$ is a principal eigenvector of the influence (importance) of the criteria in the $i^{\text {th }}$ cluster of the network on an element in the $j^{\text {th }}$ cluster. These relative importance values, which form the elements of the supermatrix, are determined using pair wise comparisons with a scale of 1-9 developed by Saaty [21] (Table 3), where a score of 1 indicates equal importance between the two elements and 9 represents the extremely more important of one element compared to the other one. The relations $a_{i j}=1 / a_{j i}$; where $a_{i j}$ denotes the importance of the $i^{\text {th }}$

Element compared to the $j^{\text {th }}$ element, and $a_{i j}=1$ are preserved in the pair wise comparison matrix to improve the consistency of the judgments [5]. It is noteworthy to mention that we need only the submatrixes that have a non-zero influence to make pair wise comparisons to derive the eigenvectors.

\section{Results and Discussion}

In order to find choose the preference for the mobile communication operators, the project team members applied the ANP model.

First, all criteria are investigated and interactions between them are identified. Therefore project team forms the decision network with these criteria and determined the inner and outer dependencies. As shown in Figure 4 this network consists of six main clusters of criteria and one cluster of alternatives.

Afterward, to construct super-matrix and assess the relative importance between criteria, the questionnaire has been designed. So, the mobile phone users are asked to respond through a series of pair wise comparisons, a part of which depicted at Figure 7, individually to elicit the preferences of them when selecting a mobile communication operator. These pair wise comparisons are based on Saaty's nine

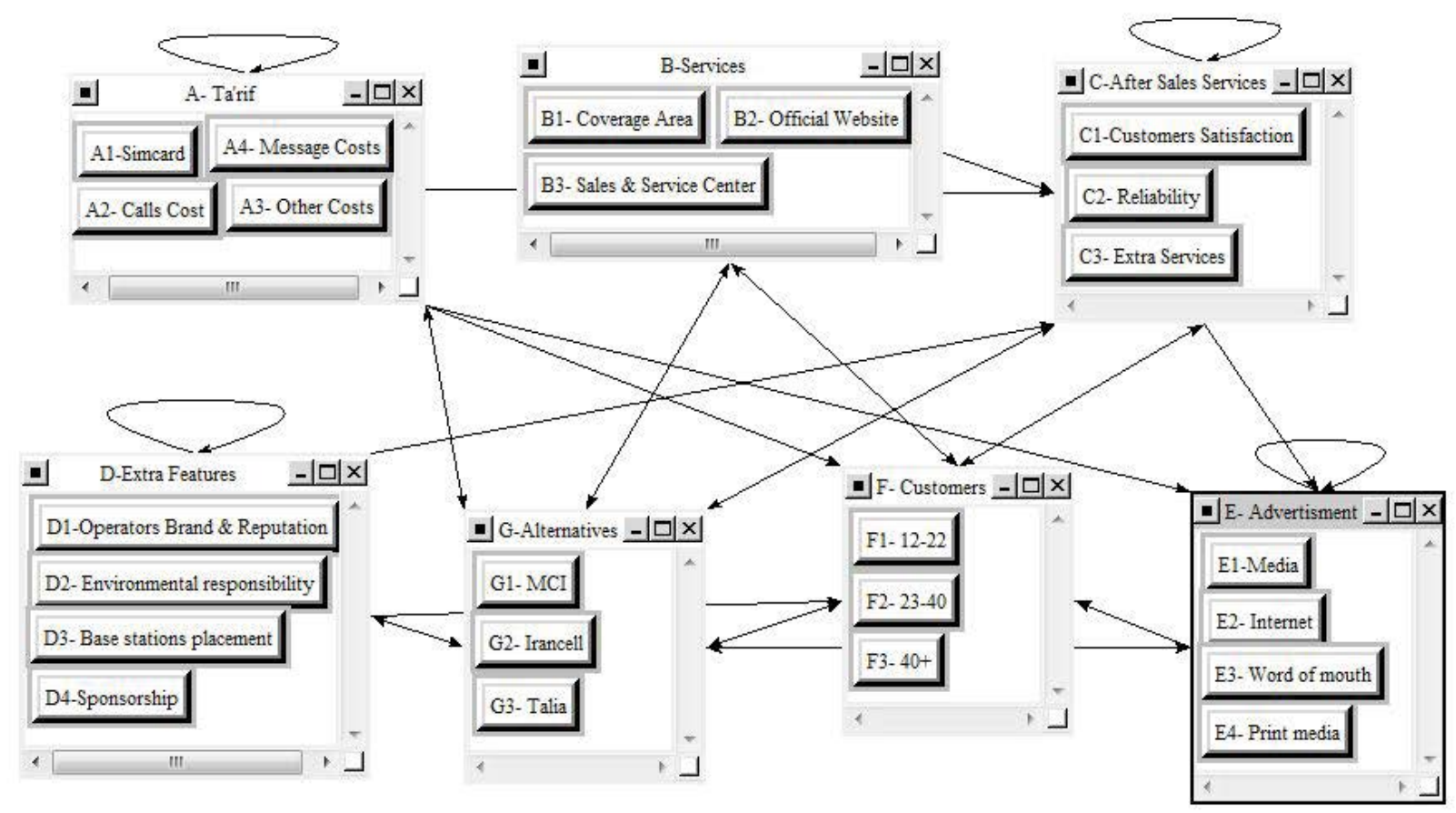

Figure 4: The network structure of the proposed ANP. 


$\left[\begin{array}{lllllll}W_{12} & 0 & 0 & W_{14} & 0 & 0 & 0 \\ 0 & 0 & 0 & W_{24} & 0 & 0 & W_{27} \\ W_{31} & W_{32} & W_{33} & W_{34} & W_{35} & 0 & W_{37} \\ W_{41} & W_{42} & W_{43} & 0 & W_{45} & W_{46} & W_{47} \\ 0 & 0 & 0 & W_{54} & W_{55} & 0 & 0 \\ W_{61} & 0 & W_{63} & W_{64} & 0 & W_{66} & 0 \\ W_{71} & W_{72} & W_{73} & W_{74} & W_{75} & W_{76} & 0\end{array}\right]$

Figure 5: General Version of super-matrix.

point scale Table 3 and represent how many times one criteria is more important than another criteria (both in the same cluster) with respect to an element in other cluster which have interaction with it. This question is asked about all elements of clusters with respect to affecting criteria, which are known as control criteria. So the submatrixes are constructed and the super-matrix is achieved. After using the geometric mean method to aggregate the opinion of mobile phone users, the unweighted super-matrix is made. Figure 6 shows this aggregated super matrix. Then, to get the weighted super-matrix, firstly the influence of the clusters on each cluster with respect to the control criteria (which is one of the clusters at each time) is determined. This yields an eigenvector of influence of the clusters on each cluster. Then the unweighted super-matrix is multiplied by the priority weights from the clusters, so the weighted super-matrix is achieved.

Finally, in order to derive the alternatives priorities, the supermatrix must become steady. For this reason the weighted super- matrix must be multiplied by itself until the super-matrix's row values converge to the same value for each column of the matrix. Therefore the super-matrix with limiting priorities is achieved. We utilize the "Super Decision 1.6" software to attain these matrixes. The global preferences for the alternatives, the forecasted market shares of the mobile operators, and the relative importance of the factors can be seen in Table 5 and Table 6 respectively.

As concluded from the obtained results in Table 5, MCI has become the most preferred mobile communication operators among three alternatives due to the highest priority of $50.54 \%$; while Irancell and Taliya have positioned at the second and third ranks with $42.36 \%$ and $7 \%$. These priorities represent the forecasted market share of each operator. The actual market share values for the mobile operators are $52 \%$ for MCI, $45 \%$ for Irancell, and 3\% for Taliya. It is obvious that results are near to reality. Figure 8 show the actual and forecasted market share.

According to limiting priorities in Table 6, the most important factor is the customer satisfactions due to the highest priority of 0.1769 . This factor have not mentioned as important factor in previous studies. The second important factor is word of mouth with priority of 0.1582 .The importance of this factor has been investigated in previous works $[7,8]$. This reveals that mobile communication operator should attempt to be customer-centric for achieving customer satisfaction because both sub-criteria customer satisfaction and word of mouth imply the important role in customer-centric perspective. The next factor is extra services (0.0924), e-banking services, contests and so on, shows that mobile communication operator should be creative in this field and offer more interesting services in order to be successful in competitive. It should be said that this factor have not mentioned as importance factor in previous studies. And finally the fourth factor that affects choosing the mobile operator is 12-25 age customer segments. So the mobile communication operator should pay more attention to

\begin{tabular}{|l|c|c|c|c|c|c|c|c|c|c|c|c|c|c|c|c|c|c|c|c|c|c|c|c|}
\hline & $\mathrm{A} 1$ & $\mathrm{~A} 2$ & $\mathrm{~A} 3$ & $\mathrm{~A} 4$ & $\mathrm{~B} 1$ & $\mathrm{~B} 2$ & $\mathrm{~B} 3$ & $\mathrm{C} 1$ & $\mathrm{C} 2$ & $\mathrm{C} 3$ & $\mathrm{G} 1$ & $\mathrm{G} 2$ & $\mathrm{G} 3$ & $\mathrm{D} 1$ & $\mathrm{D} 2$ & $\mathrm{D} 3$ & $\mathrm{D} 4$ & $\mathrm{E} 1$ & $\mathrm{E} 2$ & $\mathrm{E} 3$ & $\mathrm{E} 4$ & $\mathrm{~F} 1$ & $\mathrm{~F} 2$ & $\mathrm{~F} 3$ \\
\hline A1 & & & & & & & & & & & $*$ & $*$ & $*$ & & & & & & & & & & & \\
\hline A2 & $*$ & & & & & & & & & & $*$ & $*$ & $*$ & & & & & & & & & & & \\
\hline A3 & $*$ & & & & & & & & & & $*$ & $*$ & $*$ & & & & & & & & & & & \\
\hline A4 & $*$ & & & & & & & & & & $*$ & $*$ & $*$ & & & & & & & & & & & \\
\hline B1 & & & & & & & & & & & $*$ & $*$ & $*$ & & & & & & & & & & & \\
\hline B2 & & & & & & & & & & $*$ & $*$ & $*$ & & & & & & & & & & & \\
\hline B3 & & & & & & & & & & & $*$ & $*$ & $*$ & & & & & & & & & $*$ & $*$ & $*$ \\
\hline C1 & $*$ & $*$ & $*$ & $*$ & $*$ & $*$ & $*$ & & $*$ & $*$ & $*$ & $*$ & $*$ & $*$ & & $*$ & & & & & & & & \\
\hline C2 & $*$ & & & & $*$ & & & & & & $*$ & $*$ & $*$ & $*$ & & & & & & & & & & \\
\hline C3 & & & & & & & & & & & $*$ & $*$ & $*$ & & & & & & & & & $*$ & $*$ & $*$ \\
\hline G1 & $*$ & $*$ & $*$ & $*$ & $*$ & $*$ & $*$ & $*$ & $*$ & $*$ & & & & $*$ & $*$ & $*$ & $*$ & $*$ & $*$ & $*$ & $*$ & $*$ & $*$ & $*$ \\
\hline G2 & $*$ & $*$ & $*$ & $*$ & $*$ & $*$ & $*$ & $*$ & $*$ & $*$ & & & & $*$ & $*$ & $*$ & $*$ & $*$ & $*$ & $*$ & $*$ & $*$ & $*$ & $*$ \\
\hline G3 & $*$ & $*$ & $*$ & $*$ & $*$ & $*$ & $*$ & $*$ & $*$ & $*$ & & & & $*$ & $*$ & $*$ & $*$ & $*$ & $*$ & $*$ & $*$ & $*$ & $*$ & $*$ \\
\hline D1 & & & & & & & & & & & $*$ & $*$ & $*$ & & & & & & & & & & & \\
\hline D2 & & & & & & & & & & & $*$ & $*$ & $*$ & & & & & & & & & & & \\
\hline D3 & & & & & & & & & & & $*$ & $*$ & $*$ & & $*$ & & & & & & & & & \\
\hline D4 & & & & & & & & & & & $*$ & $*$ & $*$ & & & & & & & & & & & \\
\hline E1 & & & & & & & & & & & $*$ & $*$ & $*$ & & & & & & & & & & & \\
\hline E2 & & & & & & & & & & & $*$ & $*$ & $*$ & & & & & & & & & & & \\
\hline E3 & $*$ & $*$ & $*$ & $*$ & & & & $*$ & & $*$ & $*$ & $*$ & $*$ & & & & & $*$ & $*$ & & $*$ & & & \\
\hline E4 & & & & & & & & & & & $*$ & $*$ & $*$ & & & & & & & & & \\
\hline F1 & $*$ & $*$ & $*$ & $*$ & & $*$ & $*$ & & & $*$ & $*$ & $*$ & $*$ & $*$ & $*$ & & $*$ & $*$ & $*$ & $*$ & $*$ & & & \\
\hline F2 & $*$ & $*$ & $*$ & $*$ & & $*$ & $*$ & & & $*$ & $*$ & $*$ & $*$ & $*$ & $*$ & & $*$ & $*$ & $*$ & $*$ & $*$ & & \\
\hline F3 & $*$ & $*$ & $*$ & $*$ & & $*$ & $*$ & & & $*$ & $*$ & $*$ & $*$ & $*$ & $*$ & & $*$ & $*$ & $*$ & $*$ & $*$ & & & \\
\hline
\end{tabular}

Figure 6: Aggregated pair wise relationship matrix. 
Citation: Hemmati S, Shapouri F, Keramati A (2013) Evaluating the Iran Mobile Communication Operators by Analytical Network Process (ANP). J Telecommun Syst Manage 2: 109. doi:10.4172/2167-0919.1000109

Comparisons wrt "B3- Sales \& Service Center" node in "F- Customers" cluster

File Computations Misc.

\begin{tabular}{l|l|l|l|l} 
Graphic & Verbal & Matrix & Questionnaire \\
\hline
\end{tabular}

Comparisons wrt "B3- Sales \& Service Center" node in "F- Customers" cluster

F1- $12-22$ is equally as important as F2-23-40

1. F1- 12-22

2. $\mathrm{F} 1-12-22$

3. $F 2-23-40$

Cluster comparisons for "C-After Sales Services"

File Computations Misc Help

\begin{tabular}{l|l|l|l|} 
Graphic & Verbal & Matrix & Questionnaire \\
\hline
\end{tabular}

F-Customers is ?????? more important than G-Alternative

\begin{tabular}{|c|c|c|c|c|c|c|c|c|c|c|c|c|c|c|c|c|c|c|c|c|}
\hline $\begin{array}{l}\text { C-After Sales } \\
\text { 1. Services }\end{array}$ & $>=9.5$ & 9 & 8 & 7 & 6 & 5 & 4 & 3 & 2 & 2 & 3 & 4 & 5 & 6 & 7 & 8 & 9 & $>=9.5$ & No comp. & E-Advertising \\
\hline $\begin{array}{l}\text { 2. C-After Sales } \\
\text { Services }\end{array}$ & $>=9.5$ & 9 & 8 & 7 & 6 & 5 & 4 & 3 & 2 & 2 & 3 & 4 & 5 & 6 & 7 & 8 & 9 & $>=9.5$ & No comp. & F-Customers \\
\hline $\begin{array}{l}\text { C-After Sales } \\
\text { Services }\end{array}$ & $>=9.5$ & 9 & 8 & 7 & 6 & 5 & 4 & 3 & 2 & 2 & 3 & 4 & 5 & 6 & 7 & 8 & 9 & $>=9.5$ & No comp. & G-Alternative \\
\hline . E-Advertising & $>=9.5$ & 9 & 8 & 7 & 6 & 5 & 4 & 3 & 2 & 2 & 3 & 4 & 5 & 6 & 7 & 8 & 9 & $>=9.5$ & No comp. & F-Customers \\
\hline E-Advertising & $>=9.5$ & 9 & 8 & 7 & 6 & 5 & 4 & 3 & 2 & 2 & 3 & 4 & 5 & 6 & 7 & 8 & 9 & $>=9.5$ & No comp. & G-Alternative \\
\hline F-Customers & $>=9.5$ & 9 & 8 & 7 & 6 & 5 & 4 & 3 & 2 & 2 & 3 & 4 & 5 & 6 & 7 & 8 & 9 & $>=9.5$ & No comp. & G-Alternative \\
\hline
\end{tabular}

Figure 7: A part of pair wise comparison questionnaire.

this group and present the interesting services in order to attract and retain them. It is noteworthy to say that this factor has been identified as the fourth important factor by Tosun et al. [7] Figure 9 shows these important factors in a chart.

Moreover, the most important factor in tariff cluster is message cost (37.5\%). 12-25 age customers' segment (46.86\%) is the most important group. Among services related factors, the most important one is coverage area (56.76\%). operator's brand or reputation has the most significant value (39.9\%) in the cluster of Extra features. Customer satisfaction $(61.07 \%)$ is regarded as the most important goal in after sales services. When advertisement is taken into consideration, the most important factor is word of mouth $(89.82 \%)$.

\section{Managerial Implication}

The proposed framework provides valuable insight into customer preference and the process of GSM's operator selection for GSM managers and practitioners. It also provides a ranking of the affecting factors according to their importance in GSM selecting process. Therefore, the managers know what to consider and what to consider more precisely in order to identifying and recruiting and retaining the customers and so increase their company's market share.
Being aware of the important factors in a valid model and emphasizing these factors during marketing activities can be a potential competitive advantage for the strategic decision making of GSM operators. Therefore, managers and practitioners can benefit from these results to gain a greater share of the market.

It can be also applied as a practical assessment tool providing an evaluation of GSM operator's market share and the overall view of the future market share. Such evaluation helps identifying areas of weakness that negatively affect success in market share.

In addition, by the proposed structure, the potential risks associated with losing the market share and customers churn can be also identified and many success difficulties can be avoided.

This approach provides GSM operator's managers and practitioners with risks regarding their company's services and products and their impact on company's market share. In addition, it is valuable to identify appropriate risk mitigation strategies and action plans to reduce potential risks.

\section{Conclusions}

In view of high competitive market in mobile telecommunication 
Citation: Hemmati S, Shapouri F, Keramati A (2013) Evaluating the Iran Mobile Communication Operators by Analytical Network Process (ANP). J Telecommun Syst Manage 2: 109. doi:10.4172/2167-0919.1000109

Page 7 of 8

operator, in this study evaluating the Iranian mobile telecommunication operators has been focused. First, an implementation framework has been constructed with exploring a comprehensive set of six main criteria and sub-criteria that were useful in the choice of mobile communication operators. To assess the relative importance between criteria and forecast the market shares of the Iranian GSM operators, the questionnaire has been designed and mobile phone users are asked

\begin{tabular}{|c|c|c|}
\hline Mobile operators & Limiting priorities (\%) & Normalized priorities (\%) \\
\hline G1- MCl & 12.65 & 50.54 \\
\hline G2- Iran cell & 10.6 & 42.36 \\
\hline G3- Taliya & 0.017 & 7.1 \\
\hline
\end{tabular}

Table 5: The priorities of the alternatives.

\begin{tabular}{|c|c|c|}
\hline Clusters and criteria & Limiting priorities (\%) & $\begin{array}{c}\text { Normalized by } \\
\text { cluster }(\%)\end{array}$ \\
\hline \multicolumn{3}{|c|}{ A-Tariff } \\
\hline A1- SIM card price & 2.32 & 19.41 \\
\hline A2- Calling costs & 2.86 & 23.88 \\
\hline A3- Other costs & 2.29 & 19.2 \\
\hline A4- message cost & 4.48 & 37.5 \\
\hline \multicolumn{3}{|c|}{ D-Extra features } \\
\hline D1- Operator's Brand or Reputation & 0.76 & 39.9 \\
\hline D2- Environmental Responsibility & 0.27 & 13.87 \\
\hline D3- Base Stations' Placement & 0.48 & 25 \\
\hline D4- Sponsorship & 0.41 & 21.23 \\
\hline \multicolumn{3}{|c|}{ C-After sales services } \\
\hline C1- Customer Satisfactions & 17.69 & 61.07 \\
\hline C2- Reliability & 2.04 & 7.03 \\
\hline C3- Extra services & 9.24 & 31.9 \\
\hline \multicolumn{3}{|c|}{ B-Services } \\
\hline B1- Coverage Area & 2.05 & 56.76 \\
\hline B2- Official Website & 0.72 & 20.02 \\
\hline B3- Sales and service center & 0.84 & 23.22 \\
\hline \multicolumn{3}{|c|}{ E-Advertisement } \\
\hline E1-media & 0.94 & 5.36 \\
\hline E2- Internet & 0.42 & 2.41 \\
\hline E3- Word of Mouth & 15.82 & 89.82 \\
\hline E4- Print Media & 0.42 & 2.41 \\
\hline \multicolumn{3}{|c|}{ F-Customer segment } \\
\hline F1- 12-25 & 5.11 & 46.86 \\
\hline F2- $23-40$ & 2.49 & 22.85 \\
\hline F3- 40+ & 3.31 & 30.29 \\
\hline
\end{tabular}

Table 6: The importance of the criteria.

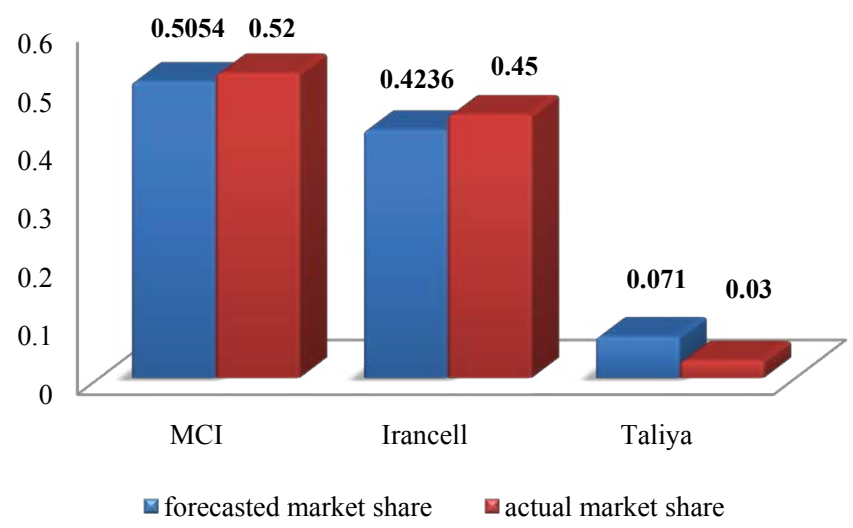

Figure 8: Actual versus forecasted market share of the alternatives.

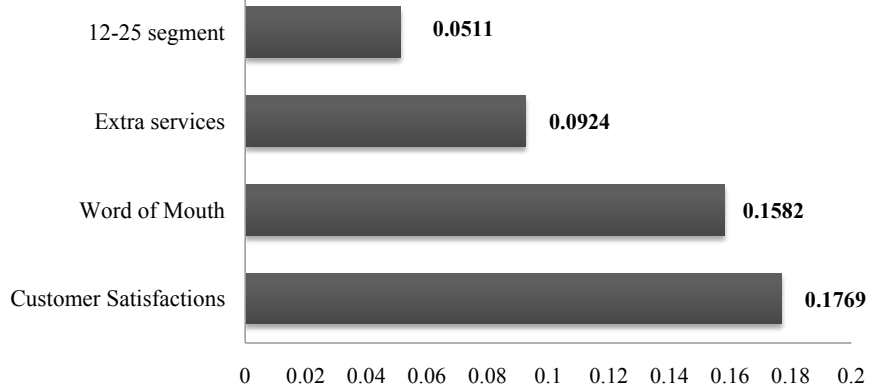

Figure 9: The limiting priority of the fourth important factor in choosing the mobile communication operators.

to respond through a series of pair wise comparisons individually. The forecasted market share values were compared with actual ones for the validation of the decision model.

It has been illustrated that Customer satisfaction, Word of mouth and Extra services such as e-banking services are the most critical factors influencing the market share of GSM's operators. The proposed framework is of great value for GSM managers and practitioners as provides valuable insight into the customer preference and the process of GSM's operator selection. It can be applied as a practical assessment tool providing an evaluation of GSM operator's market share and identifies areas of weakness that negatively affect success in market share.

As the ANP framework incorporates the inter-relationships between the factors, the authors argue that the proposed approach provides a more reliable and consistent ranking. However, the current research has some limitations that should be addressed in future works. The first limitation is related to the respondents. As we have only asked from people in one specific zone, Tehran, it will presumably create a bias in other zones of Iran. In addition, during the implementation of the ANP model, the respondents had to give the exact values to pair wise comparisons to determine the relative importance between the criteria. This process was difficult because it was not always easy to choose a crisp number that shows the relative importance of the criteria. To improve the implementation of the ANP model, it is better to use fuzzy set theory by introducing imprecise/fuzzy data.

\section{Referneces}

1. Keramati A, Seyed AMS (2011) Churn analysis for an Iranian mobile operator. Telecom Pol 35: 344-356

2. Mahatanankoon P, Wen H J, Lim B (2005) Consumer-based m-commerce: exploring consumer perception of mobile applications. Computer Standards \& Interfaces 27: 347-357.

3. Gencer C, Gurpinar D (2007) Analytic network process in supplier selection: a case study in an electronic firm. Applied Mathematical Modeling 31: 2475-2486.

4. Saaty TL (1996) Decision making with dependence and feedback: the analytic network process. 1st ed. RWS Publications Pittsburgh, USA.

5. Saaty TL (1999) Fundamentals of the analytic network process. Kobe, Japan: ISAHP.

6. Debnath RM, Shankar R (2008) Benchmarking telecommunication service in India An application of data envelopment analysis.Benchmarking: An International Journal 15: 584-598.

7. Tosun OK, Gungor A, Topcu YI (2008) ANP application for evaluating Turkish mobile communication operators. J Glob Optimi 42: 313-324.

8. Erginel N,Şenturk S (2011)Ranking of the GSM Operators with Fuzzy ANP Proceedings of the World Congress on Engineering London,UK.

9. Işıklar G, Buyukozkan G (2006) Using a multi-criteria decision making approach 
Citation: Hemmati S, Shapouri F, Keramati A (2013) Evaluating the Iran Mobile Communication Operators by Analytical Network Process (ANP). J Telecommun Syst Manage 2: 109. doi:10.4172/2167-0919.1000109

to evaluate mobile phone alternatives. Computer Standards \& Interfaces 29 : 265-274.

10. Giokas DI, Pentzaropoulos GC (2008) Efficiency ranking of the OECD member states in the area of telecommunications:Acomposite AHP/DEA study. Telecom Pol 32: 672-685.

11. Keramati A, Salehi M (2012) Website Success Comparison in the Contex of E-recruitment: An Analytic Network Process (ANP) Approach. Appl Soft Comput J 13: 173-180.

12. Ergu D, Kou G, Shi Y, Shi Y (2001)Analytic network process in risk assessment and decision analysis, Computers \& Operations Research.

13. Keramati A, Sangari MA (2011) A Success Framework to Investigate Critical Factors Associated with Implementation of Customer Relationship Management: A Fuzzy ANP Approach. International Journal of Customer Relationship Marketing and Management 2: 43-62.

14. Vinodh S, Ramiya RA, Gautham SG (2011) Application of fuzzy analytic network process for supplier selection in a manufacturing organization. Exp sys Appl 38: 272-280.
15. Salehi M, Keramati A, Didehkhani H (2010) A Framework for Investigating Mobile Web Success in the Context of E-commerce: an Analytic Network Process (ANP) Approach. J Compu Sci and Eng 4: 53-79.

16. Chen S, Zheng H (2009) A Fuzzy AHP Approach for Evaluating New Product Projects in Mobile Commerce.International Conference on Artificial Intelligence and Computational Intelligence.

17. Wu D (2009) Supplier selection: A hybrid model using DEA, decision tree and neural network. Exp Sys Appl 36: 9105-9112.

18. Maggie CYT, VMT Rao (2001) An application of the AHP in vendor selection of a telecommunications system. Omega 29: 171-182.

19. Saaty TL, Vargas LG (2006) Decision making with the analytic network process: economic political, social and technological applications with benefits, opportunities, costs and risks. Springer NewYork, USA.

20. Niemira MP, Saaty T L (2004) An analytic network process model for financialcrisis forecasting. International J Forecast 20: 573-587.

21. Saaty TL (2001) Decision making with dependence and feedback: the analytic network process, Second ed. RWS Publications Pittsburgh, USA. 